\title{
DRAWING AGAINST UNCOLLECTED CHECKS: II
}

\section{UNDERHILL MOORE, GILBERT SUSSMAN AND EMMA CORSTVET $\dagger$}

N THE introduction to the first article of this series, ${ }^{1}$ it was said that

the attention of the writers was drawn to Matter of Vavoudis ${ }^{2}$ and Smith \& Setron Printing Co. v. State of Ohio ${ }^{3}$ because the conflicting decisions in those cases, decided in different regions having possibly different cultures, offered an opportunity for making a study of the relation between the patterns of overt behavior established in the cultures and the decisions, a study in method and objectives similar to the previous studies made of debiting of direct discounts ${ }^{4}$ and of orders to stop payment of checks. ${ }^{5}$ The decisions in the two cases mentioned were made at the same time. In both cases, a customer deposited a third person's check to the credit of his checking account, the bank closed and its assets were sequestered, the check was "collected" by a receiver and the assets were increased by the amount of the check. In both cases also, there were stipulations on the deposit slips or in the passbooks which purported to state some of the consequences of the deposit. These stipulations differed in words, but as likely as not did not differ in meaning. However, the New York City judges allowed, while the Central Ohio judges denied the customer a preferred claim for the amount of the check. Does the allowance in one region and the disallowance in the other of a preferred claim support the hypothesis that decisions vary with the type and degree by which the transactions, disclosed in their records, deviate from their comparable sequences? ${ }^{b}$ Restating a fragment of this question in an oversimplified and somewhat misleading form, was the New York decision significantly associated with an established practice or pattern of overt behavior in New York City, according to which customers who have deposited third

†Underhill Moore is a Sterling Professor of Law, Yale University; Gilbert Sussman, of Portland, Oregon, is a member of the bar and was formerly a Research Assistant, School of Law, Yale University; Emma Corstvet is an Assistant Professor, Institute of Human Relations, Yale University.

This study was supported in part by a grant from the Institute of Human Relations, Yale University.

1. Moore, Sussman and Corstvet, Drawing Against Uncollected Checks: I (1935) 45 YALE L. J. 1.

2. 141 Misc. 823, 252 N. Y. Supp. 779 (Sup. Ct. 1931), aff'd without opinion, 233 App. Div. 672, 249 N. Y. Supp. 870, 233 App. Div. 814, 250 N. Y. Supp. 797 (1st Dep't 1931).

3. 40 Ohio App. 32, 178 N. E. 211 (1931).

4. Moore and Sussman, Legal and Institutional Methods Applied to the Debiling of Direct Discounts (1931) 40 Yare L. J. 381, 555, 752, 928, 1055, 1219.

5. Moore, Sussman and Brand, Legal and Institutional Methods Applied to Orders to Stop Payment of Checks (1933) 42 YALE L. J. 817, 1198.

6. See Moore and Hope, An Institutional Approach to the Law of Commercial Banking (1929) 38 YALE L. J. 703. 
persons' checks do not draw against them until after the elapsing of a period of time or the happening of an event, which period had not elapsed or event happened before the closing insolvent of the New York bank? Was the established practice or pattern in Central Ohio such that customers did draw against deposited checks and banks did honor as soon as the third person's checks were deposited or before the lapsing of some period or the happening of some event which period had elapsed or event happened before the Ohio bank closed insolvent? In short, did the decisions vary with the established practice, although that practice was not disclosed in the evidence and regardless of whether or not it was known to (i.e., in the consciousness of) court or counsel? Did the allowance in New York of a preferred claim for the amount of the deposited check and the disallowance of one in Ohio "depend" upon the time for honoring appearing in the patterns of "drawing against" deposited checks established in New York and in Central Ohio?

The securing of the data necessary for a test of the hypothesis seemed to present so much difficulty that a study was undertaken to determine the probable sufficiency of the more likely methods of securing reliable data. But this preliminary study did not cover the whole field which must be investigated were the hypothesis to be tested. It was focused on a part only of that field. In a transaction series of two sequential transactions, the first of which is the deposit of a check of a third person and the second the drawing and honoring of the depositor's check for an amount which exceeds the balance (i.e., the amount of deposit currency at the depositor's disposal) stated at the beginning of the transaction series but exceeds it by an amount no more than the amount of the deposited check, upon the happening of what event in the series of events constituting the transaction of deposit does the transaction of drawing and honoring come into institutional relation with the transaction of deposit? In other words, upon the happening of what event in the deposit transaction do banks regularly honor the depositor's check for an amount greater than the balance calculated without taking the deposited check into account, but not more than the balance so calculated plus the amount of the deposited check? Or, upon the happening of what event in the deposit transaction do banks regularly honor the depositor's check which would be an overdraft if the deposited check were not taken into account in calculating the balance? Or, upon the happening of what event in the deposit transaction is a check "drawn against" the deposit regularly drawn and honored? A study so focused required, first, that the events constituting each of the several types of deposit transactions be found, and, secondly, that the relative frequencies of "drawing against" and not "drawing against" deposited checks upon the happening of each, or at least of some, of these events be found.

The series of events constituting a deposit transaction could hardly 
be discovered by actual observation of the events as they successively happened in the depositary bank and in, for example, the post office, a bank in New York, a bank in Chicago, the Chicago clearing house, etc. It would be equally impracticable to find the events of such a transaction by a study of the records made in the several banks through which the deposited check passed in its journey from the depositor to the drawee and back to its drawer, and through which its "proceeds passed" in their journey to the depositary bank. It was judged from experience that there were but few types of deposit transactions, that each of them was established in practice, and that practically all deposits were of one of these types. It was concluded, therefore, that expertly conducted interviews with cage tellers, and officers and employees in charge of local clearing and of transit operations would be a sufficient basis for finding the series of events which constituted each of these types. Partly for this reason and partly because of the impracticability of using any other method, it was decided that in the preliminary study the findings as to the events constituting deposit transactions should be based on interviews. But the findings as to the relative frequency with which transactions of "drawing against" precede, are coincident with, or follow particular events in deposit transactions must, it was decided, be founded on an examination of the records of particular checks deposited and of particular checks drawn in the books of the banks in which the deposits were made and upon which the checks were drawn.

Most important among the records to be examined were the accounts of checking account customers in the individual ledgers. ${ }^{7}$ The difficulty of securing the consent of a bank to the examination of its individual ledger accounts for any purpose, and the even greater difficulty of securing the consent to a preliminary exploration of them made for the purpose of planning a study, led to the decision to make the preliminary study one of the transactions of a bank, closed and in the hands of a receiver for liquidation.

A closed bank was selected, the consent of competent authority and the cooperation of the receiver and his employees were secured.

To reconstruct as near as may be the series of events constituting the deposit transactions happening during the period chosen for study and recorded on the closed Bank's deposit slips and in its individual ledgers, one of the writers who was well informed as to bank operations conducted interviews with the employees of the closed Bank, with officers and employees of other banks in the same city as the Bank, with officers and employees in charge of the clearing, collection and transit operations of each of the correspondents of the Bank, and with the transit

7. Cost analysis cards, even if such records are kept, do not supply the needed information. 
managers of the New York and Boston Federal Reserve Banks. The interviews were judged to be satisfactory. From them it appears that the events constituting the deposit transactions of the closed Bank during the period covered by the study were as follows:

The deposit of a check of a third person drawn on another bank was made by a customer with a checking account either by handing it to an employee of the Bank or by mailing it to the Bank. Usually the check was accompanied by a deposit slip filled in by the customer; when it was not, the deposit slip was filled in by an employee of the Bank. The deposit slip when filled in indicated the name of the depositor, the date of the handing in, the amount of each check handed in and the bank on which it was drawn. A stipulation referring to the deposit of checlss appeared on some deposit slips but did not appear on most of them. ${ }^{8}$ From time to time during the day the deposit slips were sent to the bookkeepers who made a single credit entry for the total of each deposit slip in the individual ledger record of the customer's checking account. During the day debit entries corresponding to the amount of checks deposited were made in the general ledger of the Bank, thereby affecting the total of the Bank's demand deposit liabilities stated therein.

The checks which were received over the counter were separated by the teller receiving them into two groups, one, checks drawn on local banks, and the other, checks drawn on out-of-town banks. From time to time during the day the local checks were sent to the department charged with presenting them, the out-of-town checks to the department responsible for the collection of transit items. Checks received through the mails were, in precisely the same manner, separated into local and out-of-town checks and sent to the same departments to which they would have been sent had they been received over the counter.

Before banking hours on the morning of the day after deposit the local checks were presented by messenger to the several banks upon which they were drawn or, in the case of outlying banks, to a centrally located bank designated by the outlying bank for that purpose. In accordance with the practice of the local banks checks thus presented over the counter were not forthwith honored or dishonored but were left by the messenger with the drawee or with the centrally located bank. In the afternoon of that day, a bank having an adverse balance on the exchange of checks with another bank drew its check or draft on its out-of-town correspondent (either in Boston or New York) in favor of the other bank for the difference between the amount of the checks presented to it and the amount of the checks presented by it. If the Bank had a favorable balance on the exchange of checks with another local bank, the check which it received from that bank at the close of day was mailed to one

8. See infra, note 13. 
of its correspondents in the same manner as any other check and to the same correspondent to which other checks on the same drawee were regularly sent; in due course credit entries were made in the checking account of the Bank at its correspondent, which presented the check or forwarded it for presentment and collection in the usual way. ${ }^{9}$ The checks, presented by the Bank, which were honored by their drawees were, on the day of presentment, cancelled and debit entries for their amounts were made in the checking accounts of their drawers. The checks which were dishonored were returned to the Bank by messenger the next morning before banking hours and their amount taken into account in the settlement of the current day's balance upon the exchange of checks. As soon as possible after the receipt of the returned items a debit entry for the amount of each check was made in the account of the customer who deposited it; and, at the same time, notice of the return of the check was dispatched to the customer and steps deemed to be sufficient to charge him as a party to the check were taken.

The out-of-town checks were classified by the department responsible for the collection of transit items into (1) checks drawn on banks in a nearby city, (2) checks drawn on other banks in the First Federal Reserve District, (3) checks drawn on New York City banks and financial institutions, (4) checks drawn on any other bank in the United States. According to the practice of the Bank checks on banks in the nearby city were sent to the Bank's correspondent in that city; checks on banks in the First Federal Reserve District, other than on banks in that city and local banks, were sent to the Bank's correspondent in Boston; New York City checks to one, and always the same one, of the Bank's two correspondents in New York City; and the checks on other banks in the United States to the other, and always the other, of the two correspondents in New York City. Each of these correspondents was a member of the Federal Reserve System. After banking hours on the day of deposit the checks were mailed to the several correspondents with a covering letter, called a cash letter, listing the enclosed items sent to each.

(1) The cash letter and its enclosures addressed to the correspondent in the nearby city were received by it in its banking house before banking hours on the following day. During the morning of that day a credit entry was made in the individual ledger record of the Bank's checking account with the correspondent and an advice that a credit had been entered was mailed in time to be received by the Bank the following morning. The correspondent on the morning of the day it received the checks presented them to the banks in the nearby city on which they were drawn either through the clearing house or over the counter. In accordance with the rules and practice of the clearing house association of that city,

9. See infra, pp. $266,269$. 
clearing balances were settled for, before 3:00 P.M. on the same day, by the delivery to the banks having favorable balances of checks or drafts drawn on their Boston correspondents by the banks having adverse balances. Thus a bank having an adverse balance on the day's clearance of checks would draw a check or draft in favor of a single bank or in favor of each of two or more banks having favorable balances, depending upon the size of the debtor bank's adverse balance and the size of the creditor bank or banks' favorable balance. If the correspondent of the Bank had an adverse balance at the clearing house, then the checks received from the Bank reduced the amount of that adverse balance. If the correspondent had a favorable balance at the clearing house and received a check for its amount, the check was mailed by the correspondent to its Boston correspondent; in due course credit entries were made in the checking account of the correspondent at its Boston correspondent, which presented the check to and collected from the drawee in precisely the same manner as it did other checks on Boston banks. ${ }^{10}$ On the day of presentment, the checks, presented by the correspondent in the nearby city, which were honored, were cancelled and their amounts debited to the checking accounts of the drawers. Checks which were dishonored were returned by the drawee directly to the presenting bank before 3:00 P.M. on the day of presentment. Settlement for returned checls was made, depending upon the amount of the returned items, either by payment in cash or by the delivery of the check of the presenting bank on its Boston correspondent. Under the practice of the banks in the nearby city checks presented over the counter (to non-members of the clearing house) were presented in the morning and were not forthwith honored or dishonored, but were left by the messenger with the drawee (or its agents). During the afternoon of that day the bank which had an adverse balance on the day's exchange of checks drew its check (or draft) on its Boston correspondent to the order of the bank having the favorable balance. Checks so received by the correspondent of the Bank were mailed, credited, presented and settled for in the same manner as checks received by it from clearing house members. Checks presented over the counter by the correspondent, which were honored, were, on the day of presentment, cancelled and debit entries for their amounts were made in the checking accounts of their drawers. The checks which were dishonored were returned to it the morning after their presentment and their amount taken into account in determining the balance on the exchange of checks for that day. On the day the dishonored checks were returned to the correspondent (whether presented through the clearing house or over the counter) a debit entry for their amount was made in the individual ledger record of the Bank's checking account. The dis-

10. See infra, p. 266. 
honored checks and an advice that a debit entry for their amount had been made were, on the same day, sent to the Bank and received by it the following morning. Upon the receipt from the correspondent of the dishonored checks the Bank took the same steps to debit the accounts of their customers, to notify them and to charge them as parties to the instruments, as were taken upon the return of local checks.

It will be recalled that the correspondent in the nearby city made a credit entry in the record of the Bank's account on the day the checks and the accompanying cash letter were received by it. In determining the balance of the Bank upon which interest was allowed, the credit entry for the amount of the checks was counted as part of the balance on the day the entry was made. Again according to the availability schedule left with the bookkeepers as a guide in determining a customer's balance, beyond which amount they were instructed not to honor checks, the credit entries were, on the day of their entry, included in the Bank's available balance. And in making the monthly analysis of the Bank's account, credit entries for checks were treated, in computing the average "collected balance," as if they represented cash deposits made on the day of each entry. The checks sent to the correspondent were all drawn on banlks in the same city as the correspondent. But the interest and availability schedules provided for a delay of one or more days in counting the entries for checks drawn on banks not located in the city proper.

(2) The checks which were sent to the Boston correspondent, it will be recalled, were drawn on banks in the First Federal Reserve District and included checks drawn on any bank in that district except on local banks and on banks located in the nearby city. The cash letter and the enclosed checks were sent to the Boston correspondent after the close of business on the day of deposit and were received by it in its banking house before banking hours on the following day. Credit entries for the total amount of the checks received, whether drawn on banks in Boston or on banks located elsewhere in the First Federal Reserve District were made in the individual ledger record of the Bank's checking account during the morning of that day.

On the morning of the day they were received, all checks drawn on banks in Boston were presented to their respective drawees either through the clearing house or through the Federal Reserve Bank of Boston. In accordance with the rules and practice of the Boston Clearing House Association, favorable or adverse balances resulting from the clearing of checks were settled for by the making of credit entries in the reserve account at the Federal Reserve Bank of Boston of each member having a favorable balance and by the making of debit entries in the reserve accounts of those members having adverse balances. These entries were made in the morning of the day on which the checks were cleared and im- 
mediately upon the determination of the clearing balance of each bank for that day. In accordance with the Check Collection Time Schedule of the Federal Reserve Bank of Boston, the making of a credit entry in the reserve account of a Boston bank at the Federal Reserve Bank, for the amount of the former's favorable balance at the clearing house, forthwith increased and a debit entry forthwith decreased its legal reserve balance at the time the entry was made. Upon receipt by their drawees the checks presented through the Boston clearing house, which were honored, were canceled and debit entries for their amounts were made in the checking accounts of the drawers. Checks which were dishonored were returned to the presenting bank on the day of presentment through the afternoon return clearing of checks. These clearing balances were not settled for on that day, but credit and debit tickets were issued by the clearing house manager and were taken into account in determining each bank's clearing balance the following day. On the day the checks were returned to it, the Boston correspondent of the Bank made a debit entry for their amount in the record of the Bank's checking account. Thereupon the checks and an advice that a debit entry for their amount had been made were sent to the Bank and received by it the following morning. The Bank then took the steps usually taken upon the receipt by it of returned items.

Checks drawn on Boston banks which were not members of the clearing house and whose checks were not presented through the clearing house were delivered before 9:00 A.M. to the Federal Reserve Bank of Boston for presentment to their several drawees. In accordance with the Check Collection Time Schedule of the Federal Reserve Bank of Boston, an immediate credit was entered in the Boston correspondent's reserve account at the Federal Reserve Bank at the time the checks were delivered; and at the same time an immediate debit for the amount of the checks drawn on it was entered in the reserve account of each drawee bank. The checks were on the same day delivered by messenger to the drawee banks. Upon the receipt of these checks by their respective drawees the checks which were to be honored were cancelled and debit entries for their amounts were made in the checking accounts of the drawers. Checks which were to be dishonored were returned by the drawee bank to the Federal Reserve Bank before 3:00 P.M. on the same day. Upon their receipt by the Federal Reserve Bank credit entries were made in the account of each drawee bank for the amount of the checks returned by it and at the same time a debit entry was made in the account of the Boston correspondent to whom, on the same day, the checlss were returned. But since the checks were received by the Federal Reserve Bank after 9:00 A.M., one-day deferred credit and debit memorandum entries were made. These entries did not increase or decrease the legal 
reserve balances of the banks affected by the transaction until one day after their making, when immediate credit and debit entries were made. Before the close of business on the day the checks were returned to the Boston correspondent, a debit entry for the amount of the returned items was made in the account of the Bank and the checks and an advice slip mailed to it. The returned checks and the advice slip were received the following morning by the Bank which thereupon followed its usual procedure upon receiving returned checks.

As already pointed out, the checks drawn on banks in the First Federal Reserve District, other than on Boston banks, which were sent to the Boston correspondent of the Bank were mailed by the Bank on the day of deposit and were received the following morning by its Boston correspondent which thereupon made a credit entry for their amount in the record of the Bank's checking account. The Boston correspondent delivered the checks by messenger, before 2:30 P.M. on the day they were received, to the Federal Reserve Bank of Boston for presentment to the drawees. Upon their receipt the Federal Reserve Bank made a deferred credit memorandum entry for their amount in the individual ledger record of the Boston correspondent's reserve account with a notation of the day on which that amount was to be credited to the Boston bank's reserve account. A similar memorandum entry recording the amount of the checks drawn on it and the day such amount was to be debited to the bank's reserve account was made in the individual ledger of each drawee. According to the Check Collection Time Schedule of the Federal Reserve Bank of Boston, the amount of such checks weré to be credited to the reserve account of the forwarding bank and debited to the reserve account of the drawee bank two business days after their delivery to the Federal Reserve Bank. On the appointed day an immediate credit and an immediate debit entry were made in the respective reserve accounts. In determining the legal reserve balances of member banks immediate credit and debit entries were taken into account the day of their entry in the reserve account. On the day the checks were delivered to it, the Federal Reserve Bank mailed them direct to the several drawees. The checks were received by the drawees the next morning, the next day or, at the latest, the morning after. As soon as possible after their receipt, and during the course of that day, the checks which were honored by the drawees were cancelled and debit entries for their amounts were made in the checking accounts of the drawers. Checks which were not honored were, at the close of business on the day they were received, returned by the drawees to the Federal Reserve Bank. These returned checks were received by the Federal Reserve Bank at some time during the following day. If received by the Federal Reserve Bank before 9:00 A. M., an immediate credit for their amount was entered in the reserve account at 
The Federal Reserve Bank of the drawee bank and an immediate debit for the same amount entered in the reserve account of the Boston correspondent; and on the same day the checks were returned by messenger to the Boston correspondent. If the returned checks were not received by the Federal Reserve Bank until after 9:00 A. MI., immediate credit and debit entries in the reserve accounts of the drawee and of the Boston correspondent respectively were not made, nor were the checks returned to the Boston correspondent until the following day. Before the close of the day on which it received the returned checks, the Boston correspondent made a debit entry for the amount of the returned items in the checking account of the Bank and mailed the checks and an advice that a debit entry for their amount had been made to the Bank. The checks and the advice slip were received the following morning by the Bank which thereupon took the steps usually taken upon the return of dishonored checks.

It has been pointed out that on the morning of the day the checks were received by it, the Boston correspondent made a credit entry for their amount in the record of the Bank's checking account. In determining the Bank's balance for purposes of interest allowance, availability for drawing, and monthly analysis, etc., the credit entry, or part of it, sometimes was included on the date of entry and sometimes the date of entry merely provided a base for computation. Thus, in arriving at the balance upon which interest was allowed, the credit entry for, or that part of it which represented, the amount of checks on banks in Boston, whether presented through the clearing house or over the counter, was included on the day of entry; but that part of the credit entry which represented the amount of checks on other banks in the First Federal Reserve District was not counted as part of the balance until two business days after the date of entry. The availability schedule used in determining the balance up to which checks might be honored by the bookkeepers provided that credits for checks drawn on Boston banks were to be included in the "available" balance one calendar day after their entry and credits for checks on other banks in the First Federal Reserve District four business days after entry. In making the monthly analysis the time schedule used in determining the date upon which credit entries for checks were to be counted in calculating the "collected" balance was the same as that used in calculating the "available" balance. Credits for Boston checks were treated as cash deposits one calendar day after their entry and credits for checks on other banks in the First Federal Reserve District four business days after their entry.

(3) All checks drawn on banks and financial institutions in New York City, and only such checks, were sent to the first New York correspondent at the close of business on the day they were deposited in the 
Bank. The checks and the accompanying cash letter were received by the correspondent before banking hours on the following morning. In the morning of that day credit entries for the total amount of the checks received were made in the individual ledger record of the Bank's checking account. The correspondent on the morning of the same day presented all the checks it received to their respective drawees either through the clearing house or through the Federal Reserve Bank of New York. In accordance with the rules and practice of the New York Clearing House Association, favorable or adverse balances resulting from the clearing of checks were settled for by the exchange of credits at the Federal Reserve Bank of New York, an immediate credit being entered in the reserve account at the Federal Reserve Bank of each clearing bank having a favorable balance and an immediate debit entered in the reserve accounts of those banks having adverse balances. These entries were made in the morning of the day on which the checks were cleared and immediately upon the determination of the clearing balance of each bank for that day. According to the New York Time Schedule, an immediate credit in the reserve account of a bank at the New York Federal Reserve Bank forthwith increased its legal reserve balance at the time the entry was made; and conversely, the legal reserve balance of a bank to whose reserve account an immediate debit was entered was forthwith decreased. The drawee banks, on the day the checks were presented to them through the clearing house, cancelled those checks which were honored and made debit entries for their amounts in the checking accounts of the drawers. Checks which were dishonored were returned by the drawee banks to the first New York correspondent through the New York Clearing House Association's "Afternoon Exchange of Return Items" at 3:00 P. M. Favorable or adverse balances upon the exchange of return items were not settled for at the completion of the Afternoon Exchange of Return Items but were included in the settlement of balances on the following day. Before the close of business on the latter day a debit entry for the amount of the returned items was made in the checking account of the Bank at the first New York correspondent and the checks and an advice that a debit entry for their amount had been made was sent to the Bank. The returned checks and the advice slip were received by the Bank the following morning. It thereupon took the steps usually taken upon the return of dishonored items.

Checks drawn on New York banks whose checks were not presented through the clearing house were delivered to the Federal Reserve Bank of New York before 9:00 A. M. on the day they were received by the first New York correspondent. In accordance with the New York Time Schedule an immediate credit was entered in the correspondent's reserve 
account at the Federal Reserve Bank at the time the checks were delivered and at the same time an immediate debit entry for the amount of the checks drawn on it was made in the reserve account at the Federal Reserve Bank of each drawee bank. The making of the credit entry forthwith increased the legal reserve balance of the first New York correspondent and conversely each debit entry forthwith decreased the legal reserve balance of each drawee bank in whose reserve account an entry was made. The checks were delivered by messenger on the same day to the drawee banks. Upon receipt of these checks by their respective drawees the checks which were honored were cancelled and debit entries for their amounts were made in the checking accounts of the drawers. Checks which were dishonored were returned by the drawee banks to the Federal Reserve Bank before 3:00 P. M. on the same day. Upon their receipt by the Federal Reserve Bank a deferred credit memorandum entry was made in the account of each drawee bank for the amount of the checks returned by it with a notation of the day the credit was to become "available" as part of its legal reserve balance; at the same time a deferred memorandum debit was entered in the account of the correspondent to whom on the same day the checks were returned. According to the Time Schedule of the Federal Reserve Bank of New York credit for items on New York banks delivered to the Federal Reserve Bank after 9:00 A. M. became "available" to the forwarding bank as part of its legal reserve balance the day after the items were received by the Federal Reserve Bank. In other words, the day after the checks were returned to the Federal Reserve Bank an immediate credit was entered in the reserve account of each drawee bank for the amount of the checks returned by it and an immediate debit in the reserve account of the correspondent for the sum total of the returned checks. The legal reserve balances of the drawee banks were increased and that of the first New York correspondent decreased on the day the immediate credits and debits were made, that is, on the day after the items were returned to the Federal Reserve Bank. Before the close of business on the day the checks were returned to it a debit entry for the amount of the returned items was made in the record of the Bank's checking account at its first New York correspondent and the checks and an advice that a debit entry for their amount had been made were sent to the Bank. It received the returned checks and the advice slip the following morning and thereupon took the usual steps to debit the accounts of each depositor, to notify him of the debit and to charge him as a party to the instrument.

Checks drawn on financial institutions, other than banks, in New York City were presented to their several drawees through the City Collection Department of the New York Clearing House. All such checks received 
by the Bank's first New York correspondent were, before 10:00 A. M. on the day they were received, delivered by messenger to the City Collection Department. A due bill or receipt, prepared by the correspondent, for the amount of the checks thus presented was signed by the manager of the clearing house and returned to the messenger. The due bill was presented to the clearing house the following morning and taken into account in arriving at the correspondent's clearing balance for that day. The checks were, on the day received by the clearing house, presented by its messenger to the several drawees each of whom, upon the presentment of the checks drawn on it, "settled for" them by delivering a certified check for their amount drawn on a member bank of the New York Clearing House. The checks which were honored were cancelled and debits for such of them as were drawn by customers of the financial institutions (some may have been drawn by the financial institutions upon themselves) were entered in the accounts of the drawers. Checks which were dishonored were, before 3:00 P. M. on the day of presentment, returned by the drawee, or its messengers, to the presenting bank which forthwith reimbursed the drawee. Before the close of business on the day the dishonored checks were returned, a debit for their amount was entered in the record of the Bank's checking account at its first New York correspondent and the checks and an advice of the debit sent to the Bank. Upon their receipt the following morning, debit entries were made, notices sent and the usual steps to charge the depositors as parties to the checks taken.

In determining the balance of the Bank upon which interest was allowed, the "available" balance up to which bookkeepers were instructed to honor checks and the "collected" balance disclosed by the monthly analysis, the credits entered by the first New York correspondent upon the receipt of the checks sent by the Bank were, insofar as they represented checks drawn on New York banks, included on the day of their entry; that part of each credit which represented checks drawn on financial institutions and presented through the City Collection Department of the New York Clearing House were counted one business day after the date of entry.

(4) All other checks, that is checks drawn on banks located anywhere in the United States except in the First Federal Reserve District and in New York City were sent to the Bank's second correspondent in New York City. The checks and the accompanying cash letter were mailed on the day of deposit and were received by the correspondent before banking hours on the following morning. In the morning of that day a credit entry for the amount of the checks received was made in the individual ledger record of the Bank's checking account at its second New York correspondent. 
All checks drawn on banks in the Second Federal Reserve District (New York, Northern New Jersey, and Fairfield County, Connecticut), except checks drawn on banks in Newark, New Jersey, were delivered to the Federal Reserve Bank before 2:30 P. M. on the day they were received by the second New York correspondent. According to the time schedule of the Federal Reserve Bank of New York the forwarding bank was not given immediate credit, but only deferred credit for such items. Consequently upon their receipt the Federal Reserve Bank made a deferred credit memorandum entry in the individual ledger of the correspondent's account for the amount of the checks with a notation of the day on which that amount was to be credited to the reserve account. At the same time a similar deferred debit memorandum entry was made in the account of each drawee for the amount of the checks drawn on it with a notation of the day on which that amount was to be debited to the reserve account. On the day noted-one calendar day after the receipt by the Federal Reserve Bank of checks drawn on banks in Bufialo, two business days after the receipt of checks drawn on banks located elsewhere in the Second Federal Reserve District-immediate credit and debit entries were made in the respective reserve accounts. The legal reserve balance of the second New York correspondent was increased by the amount of the immediate credit entry on the day of its entry and conversely the legal reserve balance of each of the drawee banks was decreased by the amount of the immediate debit entry at the time it was made. The Federal Reserve Bank, on the day the checks were received by it, mailed them directly to the several drawees. The checks were received by the drawees the next morning, the next day or, at the latest, the morning after. During the course of the day on which the checks were received by their drawees the checks which were honored were cancelled and debit entries for their amounts were made in the checking accounts of the drawers. Checks which were not honored were, at the close of business on the day they were received, returned to the Federal Reserve Bank. These dishonored checks were received by the Federal Reserve Bank at some time during the day following that on which they were returned. If received by the Federal Reserve Bank before 9:00 A. M., an immediate credit for the amount of the checks returned by each drawee was entered in its reserve account on that day and a corresponding immediate debit entry was made in the reserve account of the second New York correspondent. If received by the Federal Reserve Bank after 9:00 A. M., credit and debit entries were not made in the reserve accounts until the following day though deferred debit and credit memorandum entries were made on the day of receipt. The Federal Reserve Bank delivered the dishonored checks by messenger to the Bank's second New York correspondent. Before the close of the 
day on which it received the returned checks, the correspondent made a debit entry for their amount in the record of the Bank's checking account, and the checks along with an advice that a debit entry for their amount had been made were sent to the Bank. The checks and the advice slip were received by it the following morning. On the same morning debit entries were made in the account of each depositor for the amount of the returned checks deposited by him; at the same time a notice that a debit entry had been made was despatched to the customer and steps deemed to be sufficient to charge him as a party were taken.

On the day the checks were received by the Bank's second New York correspondent it despatched those checks drawn on banks in Newark, New Jersey, to the Newark correspondent. The checks were received by the Newark correspondent either on the day they were sent or early the following morning in time to be presented that day. The checks were presented to the several Newark drawees either through the clearing house or over the counter. Upon the receipt of these checks by their respective drawees the checks which were honored ${ }^{\circ}$ were cancelled and debit entries for their amounts were made in the checking accounts of the drawers. Checks which were dishonored were, on the day of their presentment, returned to the Newark correspondent of the New York bank. The Newark correspondent on the same day returned such checks to the Bank's second New York correspondent by whom they were received on the following day, i.e., the day after they were presented to the drawees. Before the close of business on that day a debit entry for the amount of the returned items was made by the New York correspondent in the checking account of the Bank and the checks and an advice that a debit entry for their amount had been made were mailed to it. The returned checks and the advice slip were received the following morning by the Bank, which thereupon took the steps usually taken upon the return of dishonored checks.

Checks sent to the second New York correspondent and drawn on banks located elsewhere than in the Second Federal Reserve District were not always forwarded by it to the drawee in the same way, but either of two courses was followed. Some checks were sent directly to a Federal Reserve Bank. Others were sent to a correspondent of the second New York correspondent. Both these methods were used to collect checks in the same locality. Each process of collection will be described separately.

Before proceeding to describe the process by which checks were collected through the Federal Reserve System, it will be necessary to make a few observations with respect to the organization of the Federal Reserve System insofar as it bears on the collection of checks. The United States is divided into twelve territorial districts, called Federal Reserve 
Districts. In each of these districts is one Federal Reserve Bank. Some of the Federal Reserve Districts are subdivided into two or more subdistricts. In one of these subdistricts is the Federal Reserve Bank and in each of the others is a Federal Reserve Branch Bank. Checks are sent to the Federal Reserve Bank in the district, or, if the district be divided, to the Federal Reserve Bank or Branch Bank in the subdistrict in which the drawee bank is located. A check drawn on a bank in a city in which a Federal Reserve Bank or a Branch Bank is located is called a city item and will appear in the City Letter (a cash letter) sent to the reserve bank; checks drawn on other banks in the district or subdistrict in which the Federal Reserve Bank or Branch Bank is located are called country items and are included in the Country Letters (cash letters) sent to it.

The checks received by the Bank's second New York correspondent were, on the day of their receipt, sorted according to the district or subdistrict in which the drawee bank was located and according to their classification as city or country items. They were then sent, on the same day, along with accompanying City and Country Letters, to the appropriate Federal Reserve Bank or Branch Bank. At the same time that the City and Country Letters were prepared, Recapitulation Sheets, upon which appeared the amount of each City and Country Letter sent to each Federal Reserve Bank or Branch Bank, were filled in. These Recapitulation Sheets were arranged according to the number of calendar (in the case of city items) or business (in the case of country items) days that credit for such checks was deferred. According to the New York Time Schedule the number of days that credit was deferred ranged from one calendar day to seven business days. The number of days credit is deferred is based upon the average time required to "collect" the item, that is, the time from the New York correspondent to the Federal Reserve Bank plus the time to and from the drawee bank. The Recapitulation Sheets were then delivered by messenger to the Federal Reserve Bank of New York, which on that day made deferred credit memorandum entries in the account of the Bank's second New York correspondent with notations of the day upon which each deferred credit was to become available as part of that bank's reserve. On the day noted, an immediate credit entry for the amount was made in the reserve account of the correspondent, whose legal reserve balance was forthwith increased upon the making of the entry. If the checks on banks in the cities in which the Federal Reserve Banks or Branch Banks were located were received before 9:00 A. M., they were, on the day of their receipt, immediately debited to the reserve account at the Federal Reserve Bank or Branch Bank of each drawee and, in the morning of the same day, delivered by messenger to the drawee; if not received until after 9:00 
A. M., deferred debit memorandum entries were made on the day of receipt but immediate debit entries and presentment were not made until the following day. In the case of checks drawn on banks in the adjacent country, on the day of receipt, a deferred debit memorandum entry was made in the account of each drawee bank at the Federal Reserve Bank or Branch Bank (with a notation of the day on which an immediate debit was to be made) and the checks were mailed to the drawee. On the day noted an immediate debit, forthwith decreasing the drawee bank's legal reserve balance, was entered in its reserve account.

The accounts of the Federal Reserve Bank of New York, which had credited the reserve account of the Bank's second New York correspondent, and of the Federal Reserve Banks or Branch Banks, which had debited the reserve accounts of the drawees, were settled through the Gold Settlement Fund at Washington. The Gold Settlement Fund is a fund owned by the Federal Reserve Banks and held by the Treasurer of the United States in the name of the Federal Reserve Board. Ownership in the fund, which is represented by entries on books maintained by the Federal Reserve Board at Washington, is transferred from one bank to another by mere entries in the records. The Federal Reserve Check Collection System provides that at the close of each business day each Federal Reserve Bank and direct-settling branch bank telegraph the settling agent of the Federal Reserve Board at Washington the gross amount collected for each other Federal Reserve Bank and direct-settling branch. In accordance with this practice, at the close of business on the day the Federal Reserve Bank and direct-settling branches entered debits in the reserve accounts of the several drawees (the same day on which equivalent credits were entered in the reserve account at the Federal Reserve Bank of New York of the second New York correspondent) they included the amounts of the debits in the amounts telegraphed the settling agent at Washington to be due the Federal Reserve Bank of New York. The other Federal Reserve Branch Banks, which did not settle directly, wired their parent Federal Reserve Banks the amounts which they collected (the amounts of the debits) for the account of the Federal Reserve Bank of New York and these amounts were included by the Federal Reserve Banks in the amount telegraphed the settling agent as due that Bank. Settlements for returned checks were likewise effected through the Gold Settlement Fund. The Federal Reserve Bank or Branch Bank to which the checks were returned, deducted, on the day of return, the amount of the dishonored items, from the amount telegraphed to the settling agent to be due the Federal Reserve Bank of New York.

Upon the receipt of the checks by their several drawees, those checks which were honored were cancelled and debit entries for their amounts 
were made in the checking accounts of the drawers. Checks which were dishonored were, before close of business on the day of their receipt by their drawees, returned to the Federal Reserve Bank or Branch Bank which had presented them. On the day the dishonored items were received by the Federal Reserve Bank or Branch an immediate credit for the amount of the checks returned by each drawee was entered in its reserve account, forthwith increasing its legal reserve balance; on the same day the checks were returned by the Federal Reserve Bank or Branch Bank to the Federal Reserve Bank of New York. The Federal Reserve Bank of New York, upon receiving the dishonored checks, made an immediate debit for their amount in the reserve account of the Bank's second New York correspondent and returned them to it by messenger. On the same day, the New York correspondent debited the checking account of the Bank with the amount of the dishonored checks and mailed the checks together with an advice of the debit to the Bank. After their receipt the following morning by the Bank the usual steps upon the return of dishonored checks were taken.

The second method of collection employed by the Bank's second New York correspondent was one in which checks were sent to its correspondents. Checks on banks in certain designated areas were sent to particular correspondents. The checks received from the Bank, were, on the day received, sorted according to the area in which the drawee bank was located. They were then sent, together with a cash letter, to the correspondent of the New York bank. Upon receipt of the checks the correspondent made a credit entry for their amount in the cheching account of the New York bank. The correspondent thereafter proceeded to collect the checks which it had received by presenting the local checks through the clearing house or over the counter and by forwarding the out-of-town checks to the drawees, either through the Federal Reserve System or through its own correspondents. Dishonored checks were in due course returned to the New York bank's correspondent, which entered debits for their amounts in the New York bank's checking account and returned them to it. The New York bank on the receipt of the dishonored checks debited them and returned them in the usual way to the Bank, which upon receiving them likewise took the steps usually taken.

It will be recalled that, on the day the checks were received by the second New York correspondent, a credit for their amount was entered in the Bank's checking account. The credit entry was thus made without respect to either the location of the drawee bank or the process by which the checks were forwarded for collection. In no case, however, in determining the Bank's interest balance, or its "available" balance, was the entry included in the balance on the date of entry; the date 
of entry merely provided the basis for applying particular schedules which were prepared solely with respect to the location of the drawee bank. In the application of these schedules no attention was paid by the second New York correspondent to the particular process employed for forwarding checks for collection; whether checks were sent direct to its own correspondents or to a Federal Reserve Bank was immaterial. The schedules were uniformly applied to credits for all checks.

The schedule used in determining the balance upon which interest was allowed provided for a delay of no days after entry, in the case of a credit for New York City checks of which there were none, to a delay of seven business days, in the case of a credit for checks drawn on certain banks in the Twelfth Federal Reserve District, the number of days depending upon the location of the drawee bank. Thus a credit for checks drawn on banks in Buffalo or Philadelphia was counted as part of the interest balance one calendar day after its entry, while a credit for checks drawn on banks in Idaho or Arizona was not included in the balance upon which interest was paid the Bank until seven business days after the day upon which it was entered. The availability schedule according to which the Bank's "available" balance was computed provided that credit entries were not to be included until three calendar days after the day upon which the credit would be counted in arriving at the interest balance. Thus the credits for checks on banks in Buffalo or Philadelphia and in Idaho or Arizona were available four and ten days, respectively, after the date of entry. The schedule used in the monthly analysis of the Bank's daily and average collected balance was the same as that used in arriving at its "available" balance.

In addition to securing the evidence upon which to find the events constituting the deposit transactions of the closed Bank during the period chosen for study, there was the task of securing the evidence upon which to find the relative frequencies, during the period chosen for study, of "drawing against" and not "drawing against" deposited checks upon the happening of each, or at least of some, of the series of events which constituted the deposit transactions.

The period for study was selected with reference to two considerations. The first of these was the need of a period sufficiently antedating the insolvency of the Bank so that any irregularities incident to its closing would not affect the representative character of the material to be used; the other was the desire to select the most recent representative period. It was decided that the period chosen should terminate a month or more before the date of the Bank's closing. Within the limits dictated by this decision, the exact dates of the period chosen were a matter of chance. It was the practice of the Bank to keep the recent deposit slips 
(which of course would be the records first resorted to) readily available. They were placed in small boxes, each of which held the deposit slips of six to eight days. In one of these was contained the deposit slips of November 10 to November 18, inclusive. The dates of this group of deposit slips satisfied the required standards more closely than the dates of any other similar group of deposit slips. Consequently, the period chosen for study was November 10 to November 18, inclusive.

Since the study was designed to observe the frequency with which drawing and honoring transactions occurred upon the happening of some of the events in deposit transactions, it was necessary to trace the accounts of those persons who deposited checks during the sample period. For the purpose in hand, John Jones and John Jones, Trustee, were considered to be two persons. Each deposit slip was examined and the name of each person who deposited a check or collection item was listed. "Check" was defined so as to include all checks except those drawn on the Bank itself. Persons whose only transactions with the Bank were discounts of notes, deposits of cash, deposits of money orders, deposits of part of, but not the entire amount of, a single check (the transaction was treated as if the check had been "cashed" over the counter and part of the money handed over were redeposited), or in whose favor a deposit slip for the refund of a service charge had been filled in were not classified as check-depositors.

An alphabetical list of check-depositors of each day was made. A master list of check-depositors during the period was then compiled from these daily lists. The names were arranged on the master list in alphabetical order, in the same manner in which names were listed in the local City Directory. To insure that the names would be correctly listed, and that duplications would be eliminated, the employees of the Bank (then engaged in liquidating the Bank's assets, and so readily accessible) were consulted and records examined. Each name in the master list was compared with the list of checking account depositors appearing in the receiver's record of claims against the insolvent Bank and with the individual ledger cards and the signature cards kept by the Bank.

The number of check-depositors in the master list totalled 1170. It was decided that this would be too large a number of accounts to trace and also that a much smaller number would afford representative material. In consequence one-fourth of the total number of accounts, or 292 accounts, was taken as a sample. These accounts were selected in the following manner. One of the first four customers on the master list, the second, was chosen by lot. This customer and every fourth one thereafter were selected to comprise the sample. It was later found necessary to make 12 substitutions in the sample because of the erroneous inclusion in the list of check-depositors of a few depositors who were 
found not to have deposited checks as defined. Where a substitution was necessary, the customer whose name in the master list immediately followed that of the customer chosen was selected as the substitute, i.e., the third of the group of four customers was substituted for the second. Much later and after the examination of the accounts was completed, it was discovered that 15 more of the 292 accounts did not disclose any deposits of checks as defined. Since the records of the Bank had by that time become inaccessible, it was impracticable to make substitutions. Therefore the sample was reduced to 277 .

A card was made out for each customer. On this card were recorded all the data necessary to give a complete history of the account from the deposit of the first check during the sample period until the date when the last check deposited during that period became available according to the availability schedules of the several correspondent banks. These data were obtained from the deposit slips and ledger cards of the customers whose accounts were in the sample, and from the cash letters and from the return ledgers.

From the deposit slips was obtained the following information: (1) the date of each deposit; (2) the presence or absence upon the deposit slip of a stipulation concerning the deposit of checks; (3) the number of checks deposited; (4) the total amount of the checks deposited, and the amounts drawn on banks in each locality; (5) the location of the drawee of each check and, if a local check, whether or not drawn on the Bank; and (6) the total amount of all items listed on the deposit slip. Later the amount of each check deposited and of each check drawn was noted. If two or more deposits were made in a single day each deposit was recorded separately on the cards. The deposit slips of each customer subsequent to November 18 were examined in order to determine which of the checks deposited during the sample period were "drawn against" thereafter. Sometimes this was done after some analysis of the account had been made.

The next step was to secure the information disclosed by the ledger cards. There was recorded, on the same cards upon which were entered the deposit data, (1) the date of each withdrawal, (2) the total amount of checks drawn, (3) the ledger balance at the opening and at the close of each day's business. Subsequently the amount of each check "drawn against" checks deposited and the order of its entry on the ledger card were obtained. As in the case of the deposit slips the ledger cards were examined for a sufficient period both before November 10 and after November 18 to insure that any necessary data would be at hand.

At this point each check deposited by a customer from November 10 to November 18, inclusive and, where necessary, on any day subsequent, was traced in the copies of the cash letters kept by the Bank. The 
cash letters showed the correspondent bank to which each check was sent and the number of the drawee of each check. By the use of the Key Number System of the American Bankers' Association the location of the drawee of each check was then obtained. This data served both to correct and supplement the data with respect to drawee and locality obtained from the deposit slips.

The final step was to examine the return ledgers which showed the dishonored checks returned to the Bank. It was thus possible to determine which of the checks deposited were returned and also which of the entries appearing in the ledger cards as debits, and recorded on the customers' cards as checks drawn, represented returned items. The data recorded on the customers' cards were added to or corrected in the light of the information shown by the return ledgers.

The series of events which constituted each of the several types of deposit transactions had now been found, and the data as to checks drawn and checks deposited had also been secured from the Bank's records. There remained to be found the event in the deposit transaction before, or upon the happening of which a check, "drawn against" a deposited check is regularly drawn and honored. The making of such a finding requires the determination of the frequency of "drawing against" deposited checks relative to the frequency of not "drawing against" them before or upon the happening of each, or at least of some, of the events constituting the transaction of deposit. First, there must be chosen from the almost innumerable events in a deposit transaction, the event or events the time of the happening of which is to be compared with the time of honoring checks "drawn against" the deposited check.

It was impractical to choose all the events constituting any one of the types of deposit transactions. In the first place, the events were too numerous. In the second place, it was judged that the association of happening of some of them with drawing and honoring would not be significant. In the third place, there was, in the case of some events, no certainty as to the time of their occurrence. Thus, it was not known when checks, other than those drawn on local banks, on banks in the nearby city and on Boston and New York City banks, were received by their drawees, and when such checks were debited to the accounts of the drawers; when dishonored checks were returned by their drawees; when credits and debits for the amounts of returned items were made by the correspondents; or when any other event subsequent to the return of a dishonored check to the Bank occurred. In the fourth place, it was not known which of two alternative series of events occurred in the case of some checks sent to the second of the Bank's two New York correspondents and not drawn on banks in the Second Federal Reserve District. 
The day upon which other events happened was known. Thus, there was known: the day of the check's deposit, of the making of the credit entry, of the preparation of local checks for presentment, of the filling in of cash letters and the mailing of the cash letters and checks to the several correspondents; the day of the presentment of local checks over the counter, of the settlement of balances between the Bank and local banks, of the receipt of the checks and cash letters by the correspondents, of the making of credit entries in the checking account of the Bank at the correspondent, of the presentment by the correspondent of checks on drawees in the same city in which it is located, of the settlement for checks presented locally by correspondents, of the delivery or mailing by the correspondent to the Federal Reserve Bank of checks presented to drawees through the Federal Reserve System, of the making of deferred credit and debit memorandum entries and of "immediate" credit and debit entries by the Federal Reserve Banks of Boston and New York; the day of the allowance of interest to the Bank by the correspondent; the day of the availability of the deposited check provided in the correspondents' availability schedules.

The statement that these events were known must be qualified. Since the data used in the study were not obtained from records contemporaneously made by investigators observing the events as they occurred, knowledge of the time of happening depended upon information supplied by others. In the case of some events the data were obtained from records more or less contemporaneously made by employees of the bank whose duties were to keep such records. In the case of other events, inferences in respect of their occurrence and the time of occurrence were drawn from statements of informed bank officers as to what was the regular practice of their banks, supported by sample forms of records kept, schedules used as guides, etc., and by secondary sources describing the usual practice in the same or similar situations. It is clear that the actual time of happening of events determined from such evidence is a great deal more uncertain than in the case of data secured from records. And it is recognized that, insofar as unforeseen circumstances resulted in events occurring in an order or at a time differing from the regular practice, the inferences invite an element of error. Moreover, the degee of error cannot be measured. It is judged, however, that the regular practice was adhered to so closely in fact that it is possible to proceed on the assumption that the events occurred at the time when, in accordance with the usual custom, they would have occurred.

Of course the precise hour at which the "known" events happened was impossible to discover. What is known is the day upon which the several events, in the regular course of business, occurred, although it can definitely be said of some events that they occurred before, and 
of others that they occurred after, the opening for business. This lack of exactness as to the hour of occurrence applies equally to the time of honoring checks drawn by customers of the Bank. In consequence "day" is the unit in terms of which is stated the relation in time between the honoring of checks "drawn against" and events in the deposit transactions.

Since certain of the "known" events happened on the same day as others, it was possible to combine in a single group all the events in a deposit transaction which happened in one bank on the same day. The "known" events were grouped in this manner into four clusters. The time relation between each of the four clusters of events and the honoring of checks drawn was observed. Because of the importance often attached to the arrival of the day upon which the Bank's interest balance at its correspondent is affected by the deposited check and to the arrival of the day upon which the Bank's available balance at its correspondent is affected by the deposited check, it was decided also to observe the time relation between the honoring of checks drawn and the arrival of each of these days, although no event in the deposit transaction may have occurred upon either of them. The days upon which each of the four clusters happened and the two additional days were as follows:

Day of deposit: the day upon which occurred the handing in and the taking of the check for deposit; the making of the credit entry in the customer's account at the Bank; the sorting into local and out-of-town checks; the listing of out-of-town checks on cash letters and their mailing to correspondents.

Day of presentment of local checks: the day upon which occurred the preparation of local checks for presentment over the counter and the presentment over the counter of the local checks to their respective drawees.

Day of receipt by correspondent: the day upon which occurred the receipt of the checks and cash letter by the correspondent; the maling of the credit entry for the amount of the checks in the ledger record of the Bank's checking account; the sorting of the checks by the correspondent into local and out-of-town checks; the preparation of local checks for their presentment through the clearing house, over the counter or through a Federal Reserve Bank; the presentment of local checks to their drawees; the listing of out-of-town checks upon cash letters; and the mailing or delivery by messenger of the checks and cash letters to a Federal Reserve Bank or Branch Bank or to a correspondent of the correspondent.

Day upon which the Bank's interest balance at its correspondent was affected by the deposited check.

Day upon which the correspondent's reserve balance was affected by 
the deposited check: the day upon which occurred the making of immediate credit entries in the reserve accounts of the correspondent at the Federal Reserve Banks and immediate debit entries in the reserve accounts of the drawee banks irrespective of whether deferred credit and debit entries had been made prior thereto.

Day upon which the Bank's available balance at its correspondent was affected by the deposited check.

With the clusters of events and days selected, the next step in the investigation was to scrutinize each of the accounts in the sample in order to observe which of the checks drawn and honored would be overdrafts if the checks deposited were not taken into account in calculating the balance until the happening of each of the selected clusters and days.

A uniform procedure was adopted and followed in the examination of each of the accounts. The customer's ledger balance on the morning of November 10 was taken to be a "cash balance" (i.e., the amount up to which checks are drawn and honored). To the ledger balance at the beginning of November 10, and to the computed balance at the beginning of each day of the period of study were added deposits of cash and of checks on the Bank itself made the same day. Deposits of checks (other than checks on the Bank itself) were not taken into account in calculating the balance until the day with which checks deposited and checks drawn were to be correlated.11 For example, if that day was the day for the allowance of interest, the amount of deposited checks was not added to the computed balance until that day. Consequently, the amount of the balance so computed differed, depending upon which one of the six days was being correlated with checks deposited and checks drawn. From each of the several balances so computed for each of the days of the sample period, the amount of checks drawn and honored on that day was deducted. If the balance exceeded or equalled the amount of checks drawn for the entire period before the arrival of the day with which checks deposited and checks drawn were to be correlated, the checks deposited were classified as not "drawn against." If a deposited check was not followed by a check drawn and honored before the day with which checks deposited and checks drawn were to be correlated, the deposited check was classified as "followed by no checks drawn and honored." If no one of the checks deposited by a customer was classified as "drawn against," he was classified as a customer "who did not draw

11. An exception was made in the case of the deposits of local checks. They were invariably taken into account on the day following the day of their deposit in calculating the balance.

Local checks deposited and checks drawn were related to the day of deposit only. Out-oftown checks were related to each of the other days selected as well as the day of deposit. 
against." On the other hand, if the balance was less than the amount of checks drawn at any time during the period before the arrival of the day with which checks deposited and checks drawn were to be correlated, the checks deposited"were classified as "drawn against" and the depositor was classified as a customer "who drew against."

In order to determine the number of checks deposited which were "drawn against" and the number which were not, certain arbitrary rules of computation were necessary. Two rules were formulated, one applying to checks deposited by customers and one to checks drawn by customers. Where the transactions observed consisted of one deposit transaction followed by one drawing transaction these rules were unnecessary. But in many cases the actual accounts were more complicated. The following example will illustrate the problems to be met. Customer Jones, with a ledger balance of $\$ 50$ on the morning of November 10 , deposits at one time a check for $\$ 20$, another for $\$ 40$ and a third for $\$ 60$ making his ledger balance $\$ 170$. On the same day he draws five checks in amounts of $\$ 5, \$ 15, \$ 15, \$ 25$ and $\$ 35$, totalling $\$ 95$. Obviously $\$ 45$ of the $\$ 95$ were "drawn against" checks deposited that day. But how many checks were "drawn against" checks deposited? The $\$ 50$ balance was sufficient to cover either (1) the $\$ 5$ and the two $\$ 15$ checks, (2) the $\$ 5$, one $\$ 15$ and the $\$ 25$ check, (3) the $\$ 5$ and the $\$ 35$ checks and (4) one $\$ 15$ and the $\$ 35$ check. Again, which check or checks of the three checks deposited should the $\$ 45$ drawn in excess of the $\$ 50$ balance be said to have been "drawn against"? The checks which might be said to have been "drawn against" were (1) the $\$ 20$ and the $\$ 40$ checks (2) the $\$ 60$ check (3) the $\$ 20$ and the $\$ 60$ checks or (4) the $\$ 40$ and the $\$ 60$ checks.

The first rule formulated was that there should be no attempt to determine which of the several deposited checks should be classed as "drawn against." Since the objective of the study was a determination of how frequently, in a transaction series beginning with the deposit of a third person's check, the transaction following the deposit transaction was a "drawing against," each deposit transaction so followed was listed as "drawn against." Thus, in the example given of customer Jones' account, $\$ 20, \$ 40$ and $\$ 60$ would all be listed as deposit transactions which were "drawn against."

The second rule fixed a method of determining, when several checks were drawn comprising a total greater than the balance, which of them were "drawn against" the deposited checks. According to this rule all checks drawn on any given day were numbered in the order of their recording in the customer's account in the individual ledger of the Bank.12

12. A second method of determining which of the checls drawn on any given day were "drawn against" the deposited checks was formulated and applied for comparison 
The checks were then applied in this order against the balance of that day and those entirely covered by this balance were not listed as "drawn against" the deposited checks. The others were classified as "drawn against" the deposited checks. Thus, in the example given of customer Jones' account, and assuming that the order of his withdrawals recorded in the ledger was $\$ 5, \$ 15, \$ 15, \$ 25, \$ 35$, the two checks of $\$ 25$ and $\$ 35$ would be classified as "drawn against" deposited checks before the end of the day of deposit.

The results of the examination of the accounts in the sample, made in accordance with the procedure described, are set forth in Table II. The table provides for a separation of the checks deposited into local checks and out-of-town checks, but does not provide for a separation of the deposited checks into other categories. Thus no distinction is drawn between deposited checks accompanied by deposit slips bearing a stipulation that the bank "acts only as depositor's collecting agent," etc. ${ }^{13}$ and deposited checks accompanied by deposit slips bearing no stipulation whatever. It may be suggested that such a separation should have been made, inasmuch as the stipulation might be part of the bargain and contract between depositor and bank, and might, consequently, influence the depositor to postpone drawing in an amount which would

with the method described in the text. Each check drawn by a customer on a day when he had "drawn against" a deposited check was noted on a separate slip of paper. The slips were shuffled, selected at random, and each was given a number in the order of its selection. The checks were then applied against the balance in the same manner as were checks numbered in the order of their recording on the customer's ledger. A comparison of the figures resulting from the use of the two methods of selection of the order of checks showed that they were extremely similar, in no case deviating as much as 2 per centum. The method described in the text was finally employed, both because it seemed more likely to approximate the order in which the checks were presented and honored and because its use slightly lowered the percentage of checks "drawn against."

13. On the basis of statements made by one who had been an employee of tho Bank for the last ten years, and a teller and head teller for the last seven years, of the fifteen years of its existence, it is believed that for at least seven years before the period of study and probably during the whole period of the Bank's existence there were no stipulations as to the consequences of deposits printed on signature cards, passbooks, or monthly statements. Stipulations as to the consequences of the deposits within the sample, when thoy occurred, appeared on the deposit slips accompanying the deposits. The stipulations were uniform: "In receiving items for deposit or collection, this Bank acts only as depositor's collecting agent and assumes no responsibility beyond the exercise of due care. All itcms are credited subject to final payment in cash or solvent credits. This Bank will not bo liable for default or negligence of its duly selected correspondents nor for losses in transit, and each correspondent so selected shall not be liable except for its own negligence. Thls Bank or its correspondents may send items, directly or indirectly, to any bank including the payor, and accept its draft or credit as conditional payment in lieu of cash; it may charge back any item at any time before final payment, whether returned or not, also any item drawn on this Bank not good at close of business on day deposited." 
be an overdraft were the deposited check not "collected." Perhaps, therefore, more deposited checks not accompanied by stipulations would be "drawn against" than deposited checks accompanied by stipulations. This possibility was carefully considered. Its actualization, however, was believed to be highly improbable. It was judged that there was no significant association between the presence or absence of a stipulation and not "drawing against" or "drawing against" checks deposited, in view of the use, at one and the same time, of successive editions of deposit slips, some containing stipulations and others not, in view of the apparently accidental distribution of the several editions to customers, in view of the inattentiveness of customers to printed matter on what they sign, and in view of the likelihood, in any event, of customers consulting their own convenience in the matter of when to draw.

This judgment was confirmed by an analysis of the data. Of the 92 deposit slips upon which stipulations were printed, 25 or 27.17 per centum were followed, after their reception by the Bank, by at least one check which would have been an overdraft were the checks listed on the deposit slips not taken into account until the listed checks became available to the Bank according to the availability schedule of the correspondents to which they were sent; whereas, of the 450 deposit slips on which no stipulations were printed, 68 or 15.11 per centum would have been overdrafts. Another analysis was made in which the unit was not deposit slip but check deposited or transaction of deposit. The results are shown in:

TABLE I

\begin{tabular}{|c|c|c|}
\hline $\begin{array}{l}\text { on Day of } \\
\text { Deposit }\end{array}$ & $\begin{array}{l}\text { before Day of } \\
\text { Interest Allowance } \\
\text { by Correspondent }\end{array}$ & $\begin{array}{l}\text { before Day of } \\
\text { Availability at } \\
\text { Correspondent }\end{array}$ \\
\hline no. & 280. & \\
\hline
\end{tabular}

A. Checks Deposited Accompantied by Stipulations

pondent

Checks deposited which might have been drawn against

Checks "drawn against"

Checks not "drawn against"

$\begin{array}{rrrrrr}353 & 100.00 & 160 & 100.00 & 160 & 100.00 \\ 19 & 5.38 & 51 & 31.57 & 57 & 35.62\end{array}$

A. followed by checks

B. followed by no check drawn

254

$71.95 \quad 98$

61.25

96

60.00

B. Checks Deposited Accompanied by no Stipulations

Checks deposited which might have been drawn against

Checks "drawn against"

1467

$\begin{array}{llllll}467 & 100.00 & 508 & 100.00 & 508 & 100.09\end{array}$

Checks not "drawn against"

A. followed by checks drawn

B. followed by no check drawn

Total of all checks deposited which might have been drawn against 
It appears, then, that except for the day of deposit, the percentage of checks deposited accompanied by deposit slips bearing a stipulation which were "drawn against" (31.87 and 35.62 ) was much greater than the percentage of checks accompanied by deposit slips not bearing a stipulation which were "drawn against" (15.94 and 21.85). ${ }^{14}$ The writers do not regard the figures in this table as signifying that the presence of a stipulation was causally related to "drawing against," but they do believe that the figures confirm their judgment that there was no significant association between the presence of a stipulation and not "drawing against" checks deposited.

Again it was judged that no distinction should be drawn between deposited checks of customers who were borrowers from the Bank and checks of customers who were not borrowers. Nor was a distinction made between deposited checks with reference to the average balance of the depositors, their occupation, place of residence, or the length of time they had been customers of the Bank. To test this judgment, a mass of information as to the borrowing, average balance, occupation, residence of the customer and as to the age of the account was accumulated by an examination of the Bank's credit files and signature cards and of other sources not included in the Bank's records. Unfortunately such analysis of the information as was made neither confirmed nor refuted the judgment not to draw any such distinctions between the deposited checks.

Table II is presented to show the relative frequencies of "drawing against" deposited checks and of not "drawing against" deposited checks on or before each of the days referred to in the several column headings described on page 283. Each column of the table sets forth both absolute and percentage figures of the number and amount of checks deposited, of checks deposited which were "drawn against," and of checks deposited which were not "drawn against." (Lines 1-3, 10-12) Each column of the table sets forth both absolute and percentage figures of the number and amount of checks drawn during the sample period by customers who had deposited checks during that period, of checks drawn which were "drawn against" deposited checks, and of checks drawn which were not "drawn against" deposited checks. (Lines 4-6, 13-15) Each column of the table sets forth both absolute and percentage figures of the num-

14. If analysis is made in terms of customers, dividing all depositors in the sample into (1) those at least one of whose deposit slips contained a stipulation and (2) those nono of whose deposit slips contained a stipulation, the first group contains a larger percentago of its total who "drew against" deposited checks before either the end of the day of deposit (21.62 per centum for the first group, 9.58 per centum for the second), the arrival of interest allowance (31.03 per centum for the first group, 19.86 per centum for the second), or the correspondent's availability date ( 34.48 per centum for the first group, 23.28 per centum for the second). 
ber of customers who deposited checks, who deposited checks and "drew against" them, and who did not "draw against" them. (Lines 7-9)

Lines 1-3. Line 2 of columns $1 \mathrm{~b}$ and 2 shows that of the 1152 local deposits 5.38 per centum were "drawn against" on the day of deposit. In other words, the honoring of the checks of the depositor, which would have been overdrafts were the deposited check not taken into account from the making of the deposit in calculating the depositor's balance, was concurrent (i.e., happened on the same day) with the making of the deposit in only. 5.38 per centum of the 1152 local deposits. If Table II recorded the findings made from a representative sample, this relatively infrequent concurrence on the day of deposit might, in a test of the hypothesis, be taken to establish that the two transactions were not in institutional relation, in the region of which the sample was representative, until the occurrence of some event in the deposit transaction happening subsequent to the day of deposit. If a test of the hypothesis by the Vavoudis and the Smith \& Setron Printing Co. cases required a finding as to the event happening after the day of deposit upon the occurrence of which the deposit and drawing transactions are in institutional relation, then the frequency of the association of events in local deposit transactions happening after the day of deposit with the honoring of checks "drawn against" local deposits would have had to be observed to determine when institutional relation begins, unless it were judged that the finding as to when institutional relation between out-of-town deposits and "drawings against" them begins is a sufficient basis for a conclusion as to when institutional relation between local deposits and "drawings against" them begins. But in both the Vavoudis and the Smith \& Setron Printing Co. cases, the checks which were deposited were out-of-town, and not local, checks.

Line 2 of columns 1c, 3, 4 and 6 shows that of the 668 out-of-town deposits 6.88 per centum were "drawn against" on the day of deposit. In other words, the honoring of the checks of the depositor, which would have been overdrafts were the deposited checks not taken into account from the making of the deposit in calculating the depositor's balance, was concurrent (i.e., happened on the same day) with the making of the deposit in only 6.88 per centum of the 668 out-of-town deposits. The honoring of the checks of the depositor, which would have been overdrafts were the deposited checks not taken into account until the amount of the deposited checks affected the interest balance of the Bank at the correspondent to which the checks were sent, was concurrent with some event in the deposit transaction which happened before the interest balance was affected in 19.76 per centum of the 668 deposits. The honoring of checks of the depositor, which would have been overdrafts were the deposited checks not taken into account until they were "available" to the Bank according to the availability schedule of the corres- 
pondent to which they were sent, was concurrent with some event in the deposit transaction which happened before the deposited checks became "available" in 25.14 per centum of the deposits. The honoring of checks of the depositor, which would have been overdrafts were the deposited checks not taken into account until the correspondent to which they were sent received reserve credit in accordance with the availability schedule of the Federal Reserve Bank, was concurrent with some event, in deposit transactions of the class in which a Federal Reserve Bank plays a part, which happened before reserve credit became available to the correspondent in 19.83 per centum of the 620 such deposits (line 2, column 5).

If Table II recorded the findings made from a representative sample, the fact that 19.76 per centum of the deposits were "drawn against" before the Bank was allowed interest by its correspondent might, in making a test of the hypothesis, be taken to establish that "drawing against" transactions came into institutional relation with transactions of deposit upon the happening, in the deposit transaction, of some event which happened before the interest balance of the Bank at its correspondent was affected by the deposit. The fact that 25.14 per centum of the deposits were "drawn against" before the deposited checks were available might be assumed to establish that institutional relation between such transactions is present before the arrival of the day upon which the deposited checks become available to the Bank, in accordance with the terms of the availability schedule of the correspondent to which the check is sent. And, in respect of the class of checks in the collection of which a Federal Reserve Bank plays a part, the assumption might be made that institutional relation is present before reserve credit is available to the correspondent, since 19.83 per centum of such checks were "drawn against" before Federal Reserve availability. If a test of the hypothesis by the Vavoudis and Smith \& Setron Printing Co. cases required a finding as to the precise event upon the happening of which institutional relation between out-of-town deposits and drawing transactions begins, then the frequency of the association of events in out-of-town deposit transactions with the honoring of checks "drawn against" them would be necessary.

Lines 7-9. Line 7 records the number of customers in the sample who deposited the checks deposited (line 1). Lines 8 and 9, respectively, set forth the absolute numbers and the percentages of depositing customers who, on the day of deposit or before the day or events referred to in columns 1, 2, 3, 4, 5 and 6, "drew against" and did not "draw against" deposited checks. The analysis and arrangement of the data in lines 7-9, referring to the number of customers, is the same as that in lines 1-3 which refer to the number of checks deposited, except that the unit in the former is person, whereas the unit in the latter is pattern of behavior 
or transaction. For the reason that the unit in an institutional study is a transaction, lines 7-9 could not be directly relied on to establish institutional relation, even if the sample were representative of the transactions of the banks in the region under investigation. Since many readers may be interested in customers rather than in transactions, lines 7-9, a by-product of the study, are included in Table II.

Lines 4-6. In the enumeration of checks deposited, all checks were counted whether or not they were followed by the drawing of a check during the period of study (line 1); but in the enumeration of checls drawn, only checks which were preceded by a deposit during the period of study were counted. This method of enumeration was a necessary consequence of the method of sampling which excluded accounts which did not disclose checks deposited during the period of study. In respect of checks drawn, there is, therefore, no line provided for all checks drawn whether or not they were preceded by a deposit; that is to say, there is no line corresponding to line 1, which gives the totals of all checks deposited. And there is no line for checks drawn which were not preceded by checks deposited during the period of study; that is to say, there is no line corresponding to line 3 (B). Hence no direct comparison of lines 4-6 with lines 1-3 is possible. But since every deposited check which was "drawn against" was followed by the check or checks drawn against it, the ratio of the number of checks "drawn against" deposited checks (line 5) to the number of checks drawn after but not "drawn against" deposited checks (line 6) would be the same as the ratio of the number of checks deposited which were "drawn against" (line 2) to the number of checks deposited which, though followed by checks drawn, were not "drawn against" (line 3), if in every instance there were but one check deposited and one check drawn against it. However, this was not true in many instances. Hence the ratios are not the same though in some columns they approximate each other.

Lines 10-12, 13-15 and 16. Line 10 discloses the sum of the face amounts of all checks deposited and line 13 the sum of the face amounts of all checks drawn which were preceded by checks deposited. Lines $11,12,14$ and 15 disclose the distribution of the sum of the face amounts of the checks deposited and of the checks drawn among the categories described in the legends for lines 11,12,14 and 15. These sums and their distribution cannot be directly relied on to support or to rebut the conclusions drawn from or based on lines 1-3, in respect of institutional relation. They are included in Table II, however, as a by-product of the study.

It will be noted that there is no relationship between the sum of the amounts of checks deposited (lines 10-12), the sum of the amounts of checks drawn (lines 13-15), and the sum of the amounts which would be overdrawn were the checks deposited not taken into account until 
the arrival of the day or the happening of the events specified in the several column headings. There is no relationship because the full face amount of each check drawn against a deposited check is included in the sum of the amounts of checks drawn, although the payment of the check drawn might have resulted in an overdrawing of only one cent, were the deposited check not taken into account in calculating the balance. Thus, lines 10-12 and lines 13-15 give no indication of the sum of the amounts which would be overdrawn were the checks deposited not taken into account until the day or events specified in the several column headings. But the sums of the amounts advanced which would be overdrafts have been calculated and are as follows: advances on the day of deposit, $\$ 2,241.08$; advances before the Bank's interest balance at its correspondent was affected, $\$ 5,480.75$; advances before the Bank's "available" balance at its correspondent was affected, $\$ 7,797.51$; advances before the Bank's correspondent's reserve balance at a Federal Reserve Bank was affected, $\$ 5,273.33$. The amount of interest lost to the Bank, if these advances be regarded as loans by way of overdraft, may be calculated from the amounts stated on line 16. These amounts differ from the amounts of the advances stated above, since, in measuring the loss of interest, it is necessary to take into account not only the amount of the loan, but also the period of the loan. It is convenient to express the amounts lent without interest in units of one dollar lent for one day. Thus calculated, the amounts "lent without interest" are shown on line 16. They are included in Table II because of their possible interest to bankers and economists.

This report of the preliminary study is made in the hope that it may be useful to one who is tempted to test the hypothesis by the decisions in Matter of Vavoudis and Smith \& Setron Printing Co. v. State of Olio or other like decisions. 